\title{
AAPS open social media strategy (2021- 2025)
}

Harsh S. Shah*

Social media has become an important and effective tool for researchers for direct dissemination of their research findings to a larger audience. AAPS Open recognized this trend and strategically decided to offer an ideal platform to the researchers to raise their profile via AAPS Open's social media support.

With my commitment towards supporting outreach activities in pharmaceutical field, I gracefully accepted this role as social media editor at AAPS Open. As a social media editor at AAPS Open and a subject matter expert in the pharmaceutical research field with diverse research experience at different stages of drug product life cycle, I strive to help achieve the overall goal of AAPS Open by encouraging scientists to bring their innovations reach its highest potential via high quality publications with $A A P S$ Open.

Before I further discuss AAPS Open's social media strategy, I would like to emphasize there are only 4.4 million people employed by pharmaceutical industry globally which serves a global population of 7.9 billion. The responsibility of those professionals to work on behalf of a population larger than their own field is real (International Federation of Pharmaceutical Manufacturers and Associations 2021). Other statistics from United Kingdom, suggests only one-third of the pharmaceutical professionals are researchers who are directly involved with drug discovery and drug product development. Ours is a substantial and varied community!

Social media statistics suggest the presence of about 2.8 billion accounts as of today, out of which there are about 23 million pharmacists and industry scientists who

*Correspondence: harsh.shah3@my.liu.edu

J-Star Research Inc., 6 Cedarbrook Drive, Cranbury, NJ 08512, USA are expected to actively access articles throughout the pharmaceutical journals (Badr et al. 2021). For us, AAPS Open's unique "open access" feature allows access to full article within few clicks, is an important one for the readers of our research. Plus, an open access journal with a strong social media strategy is "icing on the cake" for the authors who aim to reach the maximum audience with their discoveries.

I would like to briefly comment on how social media algorithm works and how social media team at AAPS Open can help researchers to gain more visibility of their published work. As an example, the posts on Twitter and LinkedIn appear on the top of people's feeds based on their interests. Social media algorithms use artificial intelligence to customize posts which it may think are relevant to a particular person. This means to greatly benefit from social media, a person not only needs to follow the main page of their interest (e.g., AAPS Open) but also need to engage with the social media posts such as like, comment and/or share on the social media content posted by AAPS Open.

With a clear insight on social media algorithm and AAPS Open's long term goal, AAPS Open's social media strategy execution is listed below in three phases.

Firstly, it is important to recognize that quality of research is important as compared to quantity. One or two readers reading full paper and employing the learning in their research work is more important than a reader not willing to read a paper beyond the abstract and introduction due to poor writing and/or research quality. One of the important aspects AAPS Open recognizes is to build a small high-quality network of researchers who are actively engaged with the AAPS Open publication research content. original author(s) and the source, provide a link to the Creative Commons licence, and indicate if changes were made. The images or other third party material in this article are included in the article's Creative Commons licence, unless indicated otherwise in a credit line to the material. If material is not included in the article's Creative Commons licence and your intended use is not permitted by statutory regulation or exceeds the permitted use, you will need to obtain permission directly from the copyright holder. To view a copy of this licence, visit http://creativecommons.org/licenses/by/4.0/. 
Secondly, "Rome was not built in a day." A well-devised strategy to develop, grow and maintain an engaged community is key to the journal's success, and is built one step at a time. AAPS Open is going to build a community wherein researchers know who they want to reach out to and utilize it as a scientific resource for scientific discussions. Social media accounts can be an excellent tool to showcase and invite feedback on the journal's goals and upcoming plans.

Lastly, we aim to create posts through our social media account on weekly basis to begin with. We plan to post a quick summary of newly published articles, any special issue announcements, opinion polls, research breakthroughs, important pharmaceutical news as well as new drug approvals to keep the audience up-to-date with recent advances in the pharmaceutical field.

In summary, AAPS Open has a strategy in place to build a community and write captivating posts for articles published with AAPS Open. AAPS Open also aims to help connect the AAPS Open authors with the rest of the industry through social media platforms (LinkedIn and Twitter). Furthermore, AAPS Open can support researchers to achieve their goal of bringing their innovation by creating a summary post of their publications supported with videos as well as graphical pictures to the social media scientists, and thereby increase number of downloads and citations.

We believe it is very important for researchers to publish their work with a journal that has a sense of urgency, scientifically strong team of experts, and effective social media strategy that helps the scientist to disseminate their research work to the important pool of researchers in the pharmaceutical industry globally. During this process, we strongly encourage researchers to submit their work with AAPS Open to see for themselves these advantages. In the meantime, follow us or join the conversation at Twitter (https://twitter.com/AAPSOpen) and Linkedin (https://www.linkedin.com/in/aaps-open-sprin ger-nature-a16747223/).

On behalf of our new Editor-in-Chief, Andrea Allmendinger, and the brand-new editorial board, I invite you to submit your articles with American Association of Pharmaceutical Scientists (AAPS) flagship open access journal AAPS Open. At AAPS Open, we commit to broadcasting high-quality publications to the broadest, and most suitable audience possible. Besides innovative research paper, we especially invite potential publications including case reports, commentaries, data notes, database articles, letters to the editor, meeting reports, reviews, perspective, mini review, position statement, rapid communication as well as conference reports. Every submission undergoes a peer review process to help ensure consistently high-quality articles which readers appreciate.

\section{Acknowledgements \\ I would like to thank J-Star Research Inc. for being very supportive in my decision of volunteering for this role at AAPS Open Journal. I would also like to thank Dr. Andrea Allmendinger and Elizabeth Yepez for their valuable insights and suggestions.}

Author's contributions

The author(s) read and approved the final manuscript.

Funding

Not applicable.

\section{Declarations}

\section{Competing interests}

The author declare that he has no competing interests. The author is the Social Media Editor for AAPS Open.

Published online: 15 November 2021

\section{References \\ Badr AF, Ismail GA, Alghuraybi RH, Lahza RZ (2021) Expanding pharmacist's educational role using virtual and social media portals before and during COVID19 outbreak. Saudi Pharm J 29(6):533-538 \\ International Federation of Pharmaceutical Manufacturers \& Associations. The pharmaceutical industry and global health facts and figures. 2021. https://www.ifpma.org/wp-content/uploads/2021/04/IFPMA-Facts-And- Figures-2021.pdf (Accessed 28 Oct 2021)}

\section{Publisher's Note}

Springer Nature remains neutral with regard to jurisdictional claims in published maps and institutional affiliations. 